\title{
一般報文
}

センサー融合システムを用いたナノファイバーウェブの Pore size 測定法

$\begin{array}{ll}\text { 崇実大学校纎維工学科 } & \text { 金 周瑢 } \\ \text { 名古屋工業大学 } & \text { 渡辺義見 } \\ \text { 信州大学繊維学部 } & \text { 金 翼水 }\end{array}$

\section{Pore Size Measurement of Nano-fiber Webs using a Sensor Fusion System}

\author{
Jooyong Kim ${ }^{* 1}$, Yoshimi Watanabe ${ }^{* 2}$, and Ick-Soo Kim ${ }^{* * 3}$
}

${ }^{* 1}$ Department of Textile Engineering, Soongsil University, Seoul, 156-743, Korea

${ }^{* * 2}$ Omohi College, Nagoya Institute of Technology, Gokiso-cho, Showa-ku, Nagoya, 466-8555, Japan

${ }^{* * * 3}$ Faculty of Textile Science and Technology, Shinshu University, 3-15-1, Tokida, Ueda 386-8567, Japan

\begin{abstract}
A sensor fusion system has been developed in order to characterize nano fiber webs under mass production. The fusion system consists of high magnification microscope and $\operatorname{CD}$ (Charged coupled device) camera combination system for web images acquisition and the two laser displacement sensors for thickness measurement. Since the images obtained from an optical microscope represent only web surface, a scale factor (the ratio of depth of focus and thickness) has been introduced to characterize the web structure as a whole. The web structures by the microscope have been compared to those by liquid flow porometer, especially in pore size distribution. It has been shown that those two structures have a strong correlation, indicating that scaling of a single layer web structure can be an effective estimation for the structure of the thick fiber webs.
\end{abstract}

(Received 14 February, 2006 ; Accepted 21 August, 2006)

\section{1. 緒 言}

ナノ繊維は体積当たりの表面積が非常に高い。このよ うなナノ繊維の特徴をフィルターに適用すると，優れた 濾過性能を持つ製品の開発が可能となる. フィルターの 性能を決める重要な構造因子としては孔径(Pore size)の大 きさと分布とが挙げられる.

この孔径を測定する代表的な方法として, 液体流出法 がある，液体流出法とは流体をフィルター試料に通過さ せ，微細な孔に液体が浸透する流速と，加えられた圧力 との関係を利用する法である.そのなかでも水銀を利用 した水銀投入法が多く用いられている。また，最大孔径 の大きさが測定できるバブルポイント法と, 大きさが知 られている既存の粒子を通過させ，通過した粒子の大き さと質量比を利用する微細網分別法(ASTMD4751-87) など が用いられている「1-5」.

しかしながら，これらの方法では，孔径を測定するた めに試料を移動させる必要があり, この試料の準備中に おいて, 外部環境により試料の性質が変化しやすい欠点 がある.また, ウェブ製造後に測定を行うため, 生産中 に孔径を測定することは不可能である。このため実時間 工程管理に適用することは困難である. また, 従来法で は，水銀または液体・固体粒子などが孔径を通過させる
際，孔径が詰まるといったクロギーング (Clogging)現象の 発生や, 張力により孔径の大きさが変形するといった短 所もある. 孔径の変形を防止し, 光学的方式は非接触方 式であるため, このような弱点を補完することが可能で ある.さらに，この方式の利点は連続的に製品の孔径を 測定できる点にある。

本研究では, 測定対象の孔径を実時間観察するため, 高倍率顕微鏡で像を拡大させた後, 付属の CCD カメラで 撮影し, パーソナルコンピュータ $(\mathrm{PC})$ に転送させる方法 を用いた。高倍率顕微鏡で観察した映像は, 顕微鏡の集 点深度 (depth of focus) の範囲内に制限されている. そこで, 光が通過できない厚さのウェブの孔径構造を測定するた めに，厚さも同時に測定することとした．特定深度から 測定された表面孔径の大きさに, 厚みにより決定される スケールファクター(Scale Factor， S.F)を掛け算すると, ウェブ全体の孔径の大きさおよび分布を効果的に推定す ることが可能になる.

\section{2. 研究方法}

ガラスレンズを用いた光学顕微鏡を使用し，拡大され た物体の像を観察した。この分解能は光源の波長および 対物レンズの球径 (numerical Aperture, NA)により決定され 
る.この関係は Abbè により,

$$
R=0.61 \times \frac{\lambda}{N A}
$$

として表現される．ここで $\mathrm{R}$ は解像度であり，入は可視 光線の波長, NA は球径である. 可視光線の波長は 200 $750 \mathrm{~nm}$ であるため, NA の值が 0.7 である場合には $174 \mathrm{~nm}$ までの識別が可能になる. 理論的に最大光学倍率は 2000 までに至る。図 1 (a) は高倍率顕微鏡Union ${ }^{\circledR}$ 社の DZ3 に Union $^{\circledR}$ ZC70 接眼レンズを装着後, Media Cybernetics ${ }^{\circledR}$ 社の 1/2”デジタル CCD カメラによって撮影した写真である. このナノファイバーウェブの写真において, NA 0.7 , 解像度は $0.48 \mu \mathrm{m}, 19$ ”モニターの倍率は 5880 倍である. 光学顕微鏡より波長が短い電子ビームが使われている電 子顕微鏡では, その分解能は〜 $0.2 \mathrm{~nm}$ までに至ることが知 られている。 そのため, オフライン方式では高い倍率ま で計測できる長所を有する，しかしながら，電子顕微鏡 によりナノファイバーウェブを観察するためには, 銀コー ティングなどの事前準備が必要不可欠である.さらに, 電子顕微鏡観察では, 通常, 試験は停止していなければ

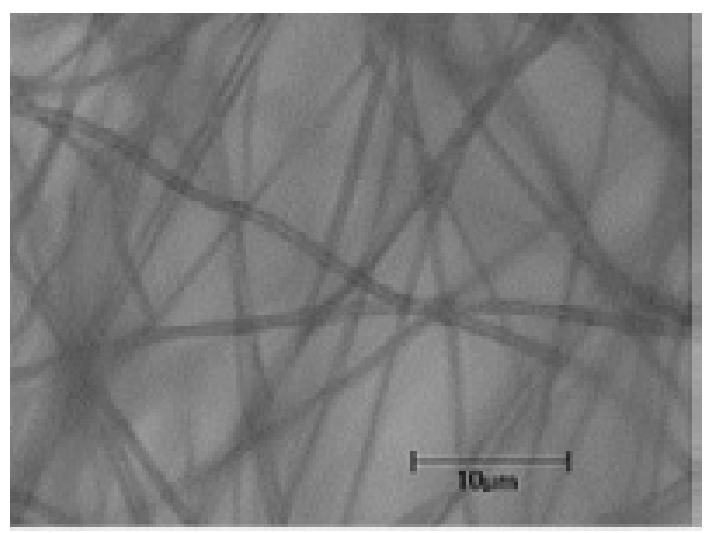

(a)

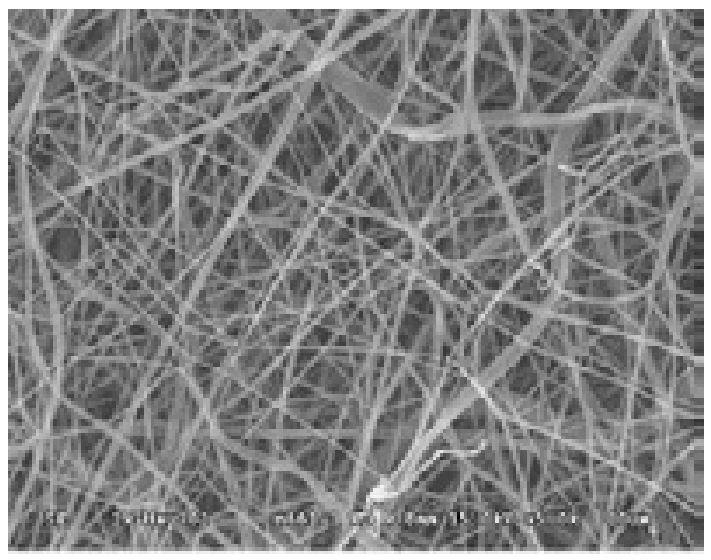

(b)

Fig. 1 The nano fiber web images (a) from high magnification zoom microscope and objective lens, (b) from scanning electron microscope.
ならず，かつ観察は電子顕微鏡室内に限定されるため, 生産工程中の計測法には適用しずらい.

光学顕微鏡による写真 $(\mathrm{a})$ と電子顕微鏡による写真 $(b, \times$ 5,000)を図 1 に示す. 図 1 (a)の光学顕微鏡写真を用いて 纎維の直径を計測したところ, 約 $\sim 1 \mu \mathrm{m}$ であることがわ かった. これらのことから, 光学顕微鏡でもナノファイ バーウェブの測定が可能であることがわかる．したがっ て, オンライン計測においても, 応用が十分可能である と判断される。ここで図 1 により，電気放射によって製 造したナノファイバーウェブは単一ウェブが厚く重なっ ている構造であることがわかる.これは工程の特性上, ウェブが形成される過程が一つずつ重ねて積もる方式で あるためである。

ここで, 本研究ではナノファイバーウェブが $\mathrm{z}$ 軸方向 の㵶維配向をもたない多層構造として仮定し, 孔径分布 を推定した．製造したウェブを高倍率顕微鏡で観察する 際は, 一定深度の表面孔径だけが測定されるため, 孔径 の大きさは実際よりも大きく測定される.

全体の孔径を正しく推定するため, 測定した表面孔径 が畿重にも積もった場合に層の数を現わすS.F を計算し, 厚さによる全体孔径の大きさを予測した. S.F を定義する と次のようになる.

$$
S . F .=\frac{F D}{T} \times 100
$$

ここで，Tはナノ纖維ウェブの厚さ，FD は深度である. (図 2).

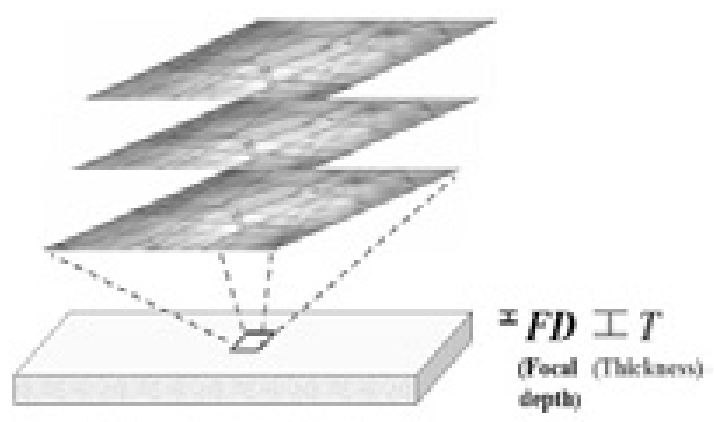

Fig. 2 Schematics of the nano fiber web multi-layered structure.

本研究では深度が分かっている試料 3 個の表面孔径に, レーザーセンサーで測定した全体ウェブの厚さを通じて $\mathrm{S}$. $\mathrm{F}$ を計算した. その後, 表面孔径にその值を代入すること でウェブ全体の孔径の大きさを，間接的に推正した。

\section{3. 実験方法}

\section{1 試料}

PAN d DMF に溶かし，さまざまな条件で放射を行い， それぞれの写真を評価した。各条件を表 1 に示す。 
ここでPre.はポリマーを押し出す力であり，Air Pre.は ノズルの横から空気をいれる際の圧力を意味する.

\section{2 測定装置}

図 3 に示すような高倍率顕微鏡 Union ${ }^{\circledR} \mathrm{DZ} 3$ に, Union ${ }^{\circledR}$ ZC50 接眼レンズおよび Media Cybernetics ${ }^{\circledR} 1 / 2 ”$ デジタル $\mathrm{CCD}$ カメラを連結した. 観察したデジタル画像を連結し たコンピューターにすぐに送信する，そして，送信した

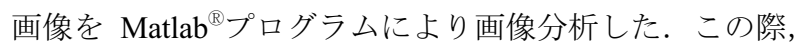
孔径の測定誤差を減らすため，顕微鏡の倍率は充分な大 きさでなければならない。 また，観察領域 (field of view) 内の孔数も十分ではないと, 統計的に有意な結果を得る ことができない。この相反する要求を元に，本研究では 最高倍率を 2100 倍, 最低倍率でも 840 倍とした。このよ うに，イメージごとに適正な倍率を実験的に決めた。こ の時，一視野の総面積は，それぞれ $397.92 \mu \mathrm{m} \times 331.6 \mu \mathrm{m}$ と $160.56 \mu \mathrm{m} \times 133.89 \mu \mathrm{m}$ である. 各試料当たりそれぞれ 10 枚の写真を撮影し，これらの写真から孔径のみを抽出 し, 分析した。平均孔径の計算分析アルゴリズムは次の ように簡単に説明できる，不織布映像から孔径の大きさ を測定する前に必要な事は孔径を㵶維から效果的に区別 することであり，明暗值 thresholding は繊維を孔径から分 離する效果的な方法である。一定の境界值を基準とし， それより明るい部分を 1 ，その他の部分を 0 に表現し，二 つ映像に現わす。この時 1 は孔径であり，0 で示された部 分は繊維になる。このアルゴルリズムの詳しい説明は, 別報にて報告予定である「6」．

ウェブ厚さの測定は，試料を顕微鏡と CCD カメラでイ メージを獲得した後, 顕微鏡で観察した所の厚みがすぐ に測定出来るようにセンサーを顕微鏡の横に付属させた

Table 1 The processing conditions for PAN dissolved in DMF.

\begin{tabular}{|c|c|c|c|c|c|}
\hline & $\begin{array}{l}\text { Conc. } \\
(w t \%)\end{array}$ & $\begin{array}{l}\text { Volt } \\
(\mathrm{kV})\end{array}$ & $\begin{array}{c}\text { Pre. } \\
\text { (kgf/cm) }\end{array}$ & $\begin{array}{l}\text { Air Pre. } \\
(\mathrm{kgf} / \mathrm{cm})\end{array}$ & $\begin{array}{c}\text { Magnification } \\
\left(\text { pixel size }=\mathbf{m}^{2}\right)\end{array}$ \\
\hline 1 & 35 & 30 & 2 & 0 & $1,260(0.223)$ \\
\hline 2 & 35 & 40 & 3 & 0.1 & $1,260(0.223)$ \\
\hline 3 & 35 & 50 & 4 & 0.2 & $1,470(0.190)$ \\
\hline 4 & 40 & 30 & 3 & 0.2 & $1,050(0.265)$ \\
\hline 5 & 40 & 40 & 4 & 0 & $1,260(0.223)$ \\
\hline 6 & 40 & 50 & 2 & 0.1 & $2,100(0.134)$ \\
\hline 7 & 45 & 30 & 4 & 0.1 & $840(0.332)$ \\
\hline 8 & 45 & 40 & 2 & 0.2 & $840(0.332)$ \\
\hline 9 & 45 & 50 & 3 & 0 & $840(0.332)$ \\
\hline
\end{tabular}

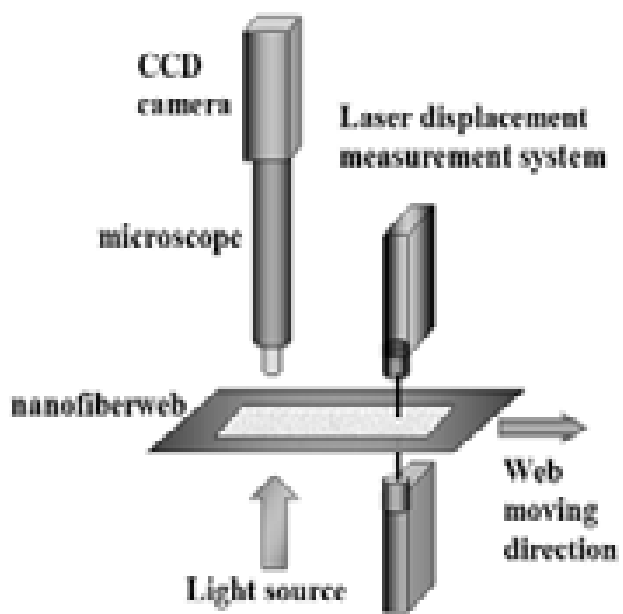

Fig. 3 Schematics of nano fiber web image acquisition.

二つの $\mathrm{KAIS}^{\circledR}$ ILD 1800-2 レーザーセンサーを向い合わせ るように連結し，厚さを測定した。この際のレーザービー ムの直径は約 $0.03 \mathrm{~mm}$ とした。顕微鏡からのイメージ収集 と厚さ測定装置を通じた厚みの情報間の時間差は，数学 的に計算する

\section{4. 結果及び考察}

\section{1 平均孔径の大きさ}

各条件による平均孔径および観察範囲を表 2 に示す. ここで示した各值は 1 枚の写真から得た数百〜数千のダ イアメーターの平均值である。試料 7 番の平均孔径が一 番大きく, 試料 6 番のそれが一番小さい. 試料 8 番およ び 9 番は，それぞれ CV\%が一番大きいおよび小さいウェ ブである

Table 2 The Pore size values obtained by the image analysis developed. $(\mu \mathrm{m})$

\begin{tabular}{lccccc}
\hline & Mean. & Max. & Min. & $\begin{array}{c}\text { Standard } \\
\text { deviation }\end{array}$ & CV\% \\
\hline $\mathbf{1}$ & 10.9861 & 12.3107 & 10.4783 & 0.626687 & 0.057044 \\
$\mathbf{2}$ & 11.34064 & 12.2819 & 10.4839 & 0.558669 & 0.049263 \\
$\mathbf{3}$ & 9.54314 & 10.0773 & 9.0768 & 0.287082 & 0.030083 \\
$\mathbf{4}$ & 14.82965 & 15.314 & 14.198 & 0.378999 & 0.025574 \\
$\mathbf{5}$ & 11.77866 & 13.5933 & 10.3767 & 0.828258 & 0.070319 \\
$\mathbf{6}$ & 8.5476 & 9.3088 & 7.919 & 0.494364 & 0.057937 \\
$\mathbf{7}$ & 22.32477 & 23.8049 & 20.7463 & 1.145978 & 0.051332 \\
$\mathbf{8}$ & 16.6157 & 19.7198 & 13.8542 & 1.599205 & 0.096247 \\
$\mathbf{9}$ & 19.36732 & 19.7306 & 19.016 & 0.267107 & 0.013792 \\
\hline
\end{tabular}




\section{2 イメージ分析法と capillary flow porometer 法 の比較}

サンプルごとにイメージ分析を用いて求めた平均孔径 の值と, capillary flow porometerを用いて求めた平均孔径 の比較を図 4 に示す。ここで用いたポロメーターは Micro Matrix 社の Auto Pro 9500 であり, Hg を試料の孔径に入れ $\mathrm{Hg}$ の圧力と量を通じて，孔径の大きさおよび分布を測定 した．図 4 に示すように，全体的に，この両者の相関関 係は 0.95 と非常に高いことが分かる.このように，提案 するイメージ分析を利用すれば，全ウェブに関する分析 が可能である.

\section{3 厚さの測定值と S.F}

上述のように，イメージ分析を用いて求めた孔のデー 夕は capillary flow porometerを用いて求めた孔径と非常に 高い相関関係を持っている.しかし，イメージ分析を用 いて求めた平均孔径は capillary flow porometerで求めた データより，わずかに大きくなる.

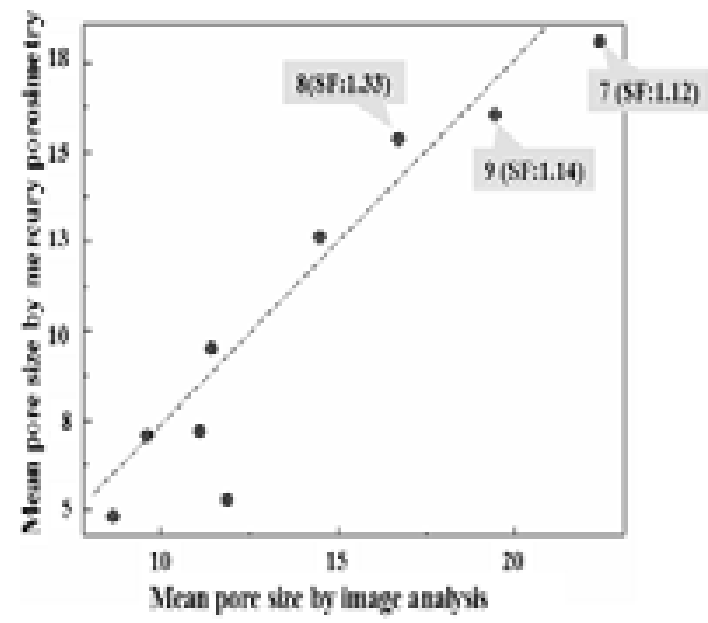

Fig. 4 The correlation (0.95) between the resulting pore sizes by image analysis and those by capillary flow porometer.

顕微鏡では表面のみを測定し，観察した值であるため, この測定データは断層構造のみを考慮した值である。全 体の厚さがわかった場合には，厚さによるスケールペッ クトを求めることができるため，このスケールファクター に相応する值を掛けると，全ウェブの孔径を予測するこ とができる．全試料に関する試料厚さのデータを表 3 に 示す.

ところで，被写界深度は顕微鏡の倍率により変化する 值であり，倍率が高ければ被写界深度は小さく，倍率が 低いと被写界深度は大きくなる。本研究では，試料番号 7 , 8 および 9 番にあたる倍率 $(\times 840)$ に対する被写界深度を 用い，3つの試料に対する分析を行った．表 4 は，この 3 種類の試料に関する被写界深度の変化を示している.

試料 7,8 および 9 番それぞれにあたる厚さの平均とこ れにより求められるスケールファクターを表わしている。
Table 3 Thickness description measured by bilateral laser sensors.(mm)

\begin{tabular}{cccccc}
\hline \hline & Mean & Min. & Max. & $\begin{array}{c}\text { Standard } \\
\text { deviation }\end{array}$ & CV(\%) \\
\hline $\mathbf{1}$ & 0.454 & 0.321 & 0.589 & 0.078 & 0.172 \\
$\mathbf{2}$ & 0.049 & 0.026 & 0.071 & 0.0095 & 0.196 \\
$\mathbf{3}$ & 0.110 & 0.039 & 0.167 & 0.029 & 0.267 \\
$\mathbf{4}$ & 0.689 & 0.571 & 0.807 & 0.071 & 0.103 \\
$\mathbf{5}$ & 1.016 & 0.875 & 0.167 & 0.056 & 0.055 \\
$\mathbf{6}$ & 0.327 & 0.286 & 0.444 & 0.027 & 0.084 \\
$\mathbf{7}$ & 0.625 & 0.568 & 0.693 & 0.030 & 0.048 \\
$\mathbf{8}$ & 0.526 & 0.412 & 0.603 & 0.061 & 0.116 \\
$\mathbf{9}$ & 0.612 & 0.555 & 0.654 & 0.025 & 0.041 \\
\hline
\end{tabular}

Table 4 The Scale Factor and mean pore size ratio between two measurement methods.

\begin{tabular}{|c|c|c|c|}
\hline Sample number & 7 & 8 & 9 \\
\hline Thickness & 0.625 & 0.526 & 0.612 \\
\hline Depth of focus & 0.7 & 0.7 & 0.7 \\
\hline Scale Factor & 1.12 & 1.33 & 1.14 \\
\hline $\begin{array}{c}\text { Mean pore size by } \\
\text { porosimetry method(P) }\end{array}$ & 17.92 & 15.49 & 16.08 \\
\hline $\begin{array}{l}\text { Mean pore size by image } \\
\text { analysis method(I) }\end{array}$ & 22.29 & 16.62 & 19.37 \\
\hline $\mathbf{P} / \mathbf{I}$ & 0.803 & 0.932 & 0.830 \\
\hline
\end{tabular}

ここで, 表 4 の一番下に示している P/I は capillary flow porometer で測定した孔径の值とイメージ分析で求めた孔 径の值である。これらのことから，スケールファクター が大きくなるにつれ， P/I が大きくなり，スケールファク ターが小さくなると值も小さくなる，これらのことから， スケールファクターが大きくなるにつれ， P/I が大きくな り，スケールファクターが小さくなると值も小さくなる. これは厚みを図る際, ナノファイバーウェブの下から光 を当てることでウェブの厚さが厚くなると $\mathrm{SF}$ は遠くなる からである. 寸なわち, 図 4 に示すように, 試料 8 番と 同じようにスケールファクターが大きい值の場合，イメー ジ分析結果の孔径結果からわずかに大きい值を掛ける．7 番と 9 番のようなスケールファクターの小さい場合は, 小さな值を掛けることで全体の孔の大きさを推正するこ とができる。 


\section{5. 結 論}

電気放射によるナノファイバーウェブの大量生産工程 中において，生産するナノファイバーウェブの孔径を分 析するための測定装置を開発した。顕微鏡を CCD カメラ と連結してイメージを撮影し，イメージ分析アルゴリズ ムで孔径の大きさを解析する。 ウェブの表面のみを観察 したイメージで求めた孔径は, 実際の孔径はより大きく 算出されることがわかった。レーザー変位計を用いた厚 さの情報を考慮し, 厚さと depth of focusの比でスケール ペックトを導入することにより，全ウェブの孔径を推定 できるシステムを開発した。これは, 実際の大量生産工 程に組み込むことができ, 孔径解析が可能な効果的なシ ステムである.このシステムは, リアルタイムモニタリ ングによるナノファイバーウェブの最適化のための工程 条件および変数制御が可能であると考えられる.

\section{Acknowledgments}

The authors of this paper would like to thank the Korea Science and Engineering Foundation (KOSEF) for sponsoring this research through the SRC/ERC Program of MOST/KOSEF (R11-2005-065) and this work was supported by the Soongsil University Research Fund.

\section{文 献}

1. A. B. Abell, K. L. Willis, and D. A. Lange, J. Colloid and Interface Sci.,39-44, (1999).

2. Dong Haw Lee, Eun Ae Kim, J. Korean Fiber Soc. , 35, 439-446 (1998).

3. Bernard Miller and LLya Tyomkin, J. of Colloid and Interface Sci., 162, 7163-170 (1994).

4. Tae Hoon Kim, Byung Ik Jun, and Min Kyu Song, $J$. Korean Fiber Soc., 34, 701-710 (1997).

5. Jin Sun Bok, Chang Whan Joo, Rae-Yohon Lee, '94 Korean Fiber Soc. autumn symposium, 32 (1994).

6. J. Y. Kim and I. S. Kim in preparation. 